\title{
INVESTIGATION OF SOURCES OF PARTICULATE MATTER FROM THE TAJGAON INDUSTRIAL AREA, DHAKA
}

\author{
BILKIS A. BEGUM ${ }^{1}$, A. TAZMIN ${ }^{2}$, K. A. RABBANI ${ }^{2}$, SWAPAN K. BISWAS $^{1 *}$ AND \\ M. NASIRUDDIN ${ }^{3}$ \\ ${ }^{1}$ Chemistry Division, Atomic Energy Centre, P.O. Box 164, Dhaka-1000, Bangladesh. \\ ${ }^{2}$ School of Environmental Science and Management, Independent University, Dhaka, \\ Bangladesh \\ ${ }^{3}$ Air Quality Management Project, Department of Environment, Agargaon, Dhaka, \\ Bangladesh.
}

\begin{abstract}
Air particulate matter (PM) level and its constituents (black carbon, organic carbon and selected trace metals) were investigated from samples of a field campaign from Tajgaon Industrial area in Dhaka City. The sampling was done from November 2006 to April 2007 using MiniVol Portable AirMetrics samplers. The samples were collected in two fractions of 0-2.5 $\mu \mathrm{m}$ and $0-10$ $\mu \mathrm{m}$ sizes using two samplers simultaneously. It has found that both $\mathrm{PM}_{10}$ and $\mathrm{PM}_{2.5}$ values were higher than the 24-h average Bangladesh national ambient air quality standard. From statistical analysis of the PM composition data coupled with reconstructed mass (RCM) technique, five major local sources could be identified those contributing to PM mass. Although PM samples were collected from an industrial area, vehicular emissions constituted the major source of air pollution and possibly some regional emission sources are also responsible for high $\mathrm{PM}_{2.5}$ and $\mathrm{BC}$ concentrations in Dhaka, especially during wintertime. It is also observed that $\mathrm{PM}_{2.5}, \mathrm{PM}_{10}$ and $\mathrm{BC}$ concentration levels at a receptor site largely depend on the meteorological conditions including rainfall, wind speed and wind direction.
\end{abstract}

Key words: $\mathrm{PM}_{10}, \mathrm{PM}_{2.5}$, MiniVol sampler

\section{INTRODUCTION}

Air pollution has become one of the serious environmental concerns in urban areas, especially in view of the adverse health effects that have been associated with ambient fine particles ${ }^{(1,2)}$. Due to enhanced human activities producing increased emissions, atmospheric pollution in urban area has become a major issue in many developing countries all over the world. The rates of increase in pollutant concentrations in the cities of the developing countries are higher than those of the developed countries ${ }^{(3)}$. Like other developing countries, up to $10 \%$ of respiratory infections and disease in Bangladesh may be attributable to urban air pollution ${ }^{(4)}$. While the problem is most severe in Dhaka, both because of worse air quality and the number of people exposed, the air pollution is also becoming a growing concern in other major cities of Bangladesh. Like other developing Southeast Asian countries, emissions from various kinds of automobiles especially, diesel vehicle and badly maintained automobiles contribute most to air pollution problems.

Ambient particulate matter $(\mathrm{PM})$ with aerodynamic diameter $<10 \mu \mathrm{m}\left(\mathrm{PM}_{10}\right)$ show short-term and chronic adverse effects on health in both children and adults ${ }^{(5-7)}$. Fine particle pollution in the atmosphere primarily consists of micron and sub-micron particles from the manmade sources such as motor vehicles, biomass, fossil fuel burning, and

\footnotetext{
${ }^{*}$ Corresponding author
} 
natural sources such as windblown soils and sea spray ${ }^{(8,9)}$. The characterization of these fine particles is becoming more important to governments, regulators, and researchers due to their potential impact on human health ${ }^{(10)}$, their ability to travel thousands of kilometers across countries, and their influence on climate forcing and global warming ${ }^{(11)}$.

Increased anthropogenic emissions of airborne heavy metals are of major concern in recent years as they are influencing urban as well as rural areas due to short and long range transport behavior of the fine particulates ${ }^{(12,13)}$. Heavy toxic trace metals carried by atmospheric particles, may change the chemical composition of metals after settling on the superficial soil, thus changing their bio-availability in the soil and water ${ }^{(14,15)}$. Particularly, industrial and automotive emissions contribute to a larger extent in this respect.

A high concentration of air pollutants such as black carbon in Dhaka City air has been reported ${ }^{(16)}$. Vehicular emissions, as well as biomass/coal burning for cooking and in the brick kilns around the city, are main contributor to these emissions ${ }^{(17,18)}$. It is also observed in previous study that PM concentration in hot spot area (proximity of major road ways) is higher than the semi-residential area in Dhaka ${ }^{(19)}$ Tejgoan, the industrial area in the Dhaka city is located along the western side of this site. Many of these industries use fuel/furnace oil as source of energy for boilers and during power cuts for stand by generators, which is common in recent time. On the other hand, Mohakhali, a growing busy commercial area, is also the traffic hub that connecting with a highway towards the north. Large number of intercity vehicles, mainly diesel buses are plying through it. There are also intercity train lines passing through this area. These varieties of vehicles use different types of fuels. Among those, significant number including the train is run by diesel, which produces significant emissions and thus contributing to the elevated levels of air pollutants.

Since, industrial emissions are believed to be a major contributor to particulate matter, this study will look at particulate matter levels in the Tejgaon area of Dhaka city. The main industries in Tejgaon are garment industries, biscuit factory, automobile repair works, shoe factory, oil mill, ice factory, beverage factory, plastic and rubber factories. Before any policy intervention can be taken for reducing PM from Tejgaon, study is needed to quantify the contribution from industrial source.

The concentrations of PM primarily depend on the location of sampling, meteorological parameters, energy use pattern in the locality. PM concentration in an airshed may also have the weekday or weekends effects. The aim of the present study is to assess the $\mathrm{PM}_{10}$ and $\mathrm{PM}_{2.5}$ levels in an industrial area with considerable traffic density and characterize them to identify the possible source of PM, especially from industrial emissions in the area.

\section{EXPERIMENTAL}

\subsection{Description of the sampler}

Airmatrics MiniVol sampler designed and developed jointly by the Environmental Protection Agency (EPA) and the Lane Regional Air Pollution Authority, USA, was used for PM sampling in this study. The sampling technique is a modification of the $\mathrm{PM}_{10}$ 
reference method described in the U.S. Code of Federal Regulations ${ }^{(20)}$ can be used for $\mathrm{PM}$ and gas sampling.

The MiniVol Airmatrics sampler is basically a pump controlled by a programmable timer, which can be set to make up to six runs within 24 hours or throughout a week. The sampler is equipped to operate from either $\mathrm{AC}$ or DC power sources. In the particulate matter (PM) sampling mode, air is drawn through a particle size separator and then through a filter medium. Particle size separation is achieved by impaction. The collection of correct particle size depends on volumetric flow rate. In case of MiniVol, the actual flow rate should be $5 \mathrm{lpm}$ at ambient conditions. To assure a constant $5 \mathrm{lpm}$ flow rate through the size separator at different air temperatures and atmospheric pressures, the sampler must be adjusted for each sampling site. Detail of the sampler and sampling procedure may be seen elsewhere ${ }^{(21)}$.

\subsection{Sampling}

The PM sampling was done at Bangladesh Industrial and Technical (BITAC) campus located at Tajgaon Industrial area (Fig. 1) in Dhaka city by the Department of Environment as part of their routine air quality monitoring program. The site is located close to an intersection of several main roads typically carrying heavy traffic. A Another heavily trafficked road is $100 \mathrm{~m}$ away from the sampling location. The sampling site is located in an unobstructed area at least $30 \mathrm{~m}$ from any obstacle to airflow. Population density is lower as compared to the average of Dhaka. The site represents mixed area (i.e., semi-residential, industrial area and commercial) in nature. Both industrial and motor vehicle sources expected to make an important contribution to long-term and peak concentrations. One of the busy bus terminals is located within a kilometer of the sampling site. A big metal workshop is also located within the immediate vicinity of the sampling site. Both $\mathrm{PM}_{10}$ and $\mathrm{PM}_{2.5}$ samples were collected under this programme. The Airmatrics samplers were placed on the rooftop of a building. The sampling probe is about 6 meter above from the ground level. The sampling was done during the weekdays.

The MiniVol was positioned with the intake upward at a height of $6 \mathrm{~m}$ above ground level. The intake nozzle of the sampler at BITAC location was about $100 \mathrm{~m}$ away from roadside. $\mathrm{PM}_{10}$ and $\mathrm{PM}_{2.5}$ were collected simultaneously for $24 \mathrm{hrs}$ at every sampling site with two MiniVol samplers. PM samples collected during November 2006 to April 2007 were used for this study, because the period covers the dry season of the year when PM concentrations expected to be higher than the rest of the time. The conditioned clean filters were loaded to respective filter holder assembly at AQMP conditioning laboratory and were brought to sampling site in separate clean polyethylene bag at each effective sampling day. After sampling, filter holder assemblies (keeping the exposed filters inside) were brought to the conditioning room of AQMP laboratory directly from the sampling site for conditioning and PM retrieval. Care was taken in transporting the exposed filter holder assemblies, so that there should be no PM loss. Standard operating procedure (SOP) for weighing air filter was followed throughout the weighing process ${ }^{(22)}$. Moisture content of a filter may affect its weight; therefore, filters were equilibrated in a conditioning environment for 24 hours before being weighed. During this equilibration period, the relative humidity and temperature were kept typically around $50 \%$ relative humidity and $22^{\circ} \mathrm{C}$ respectively. Stainless steel tweezers was used for safe filter handling. 


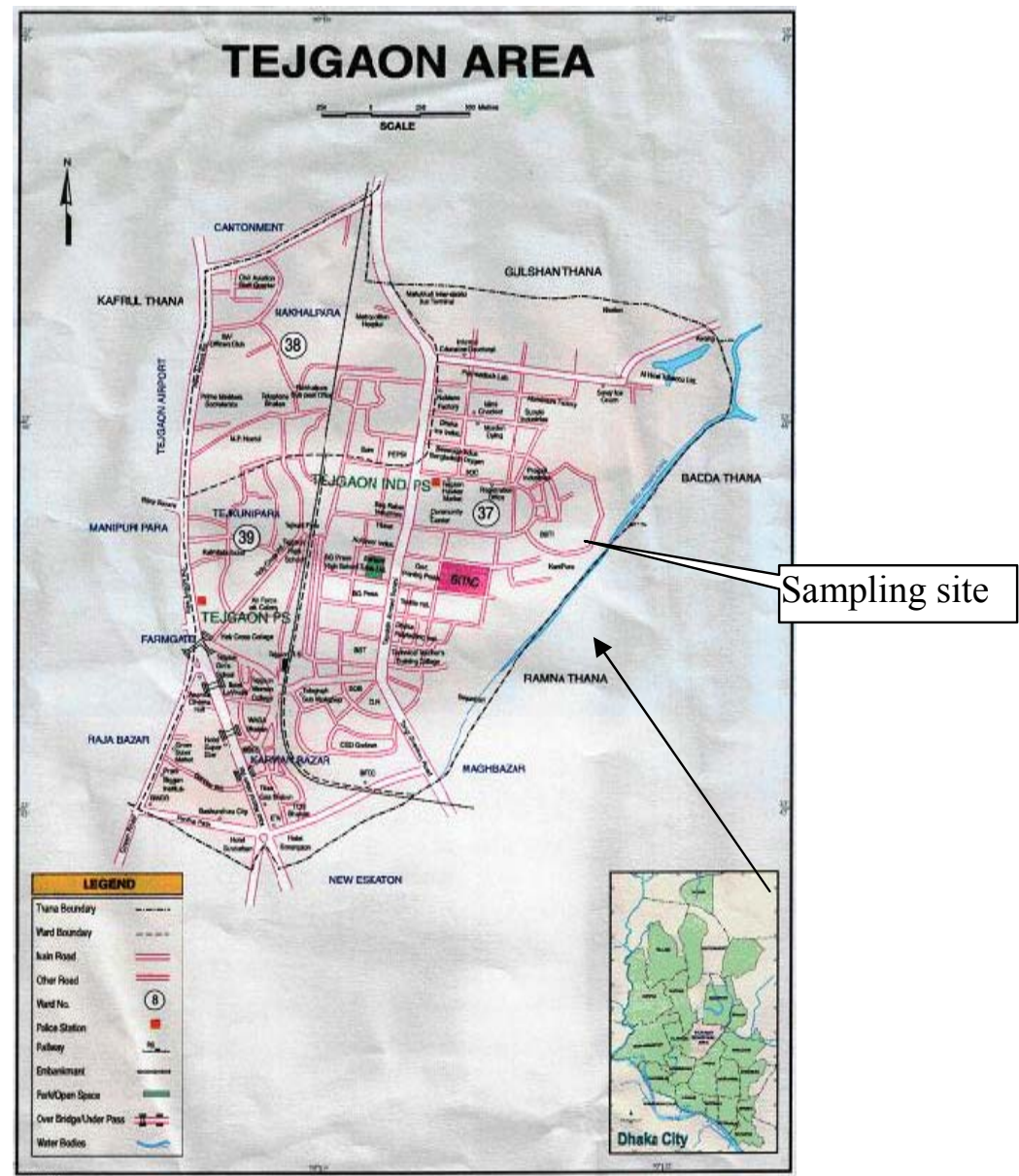

Fig. 1. Location of sampling sites at Dhaka

\subsection{PM mass and BC determination}

PM mass of the samples collected at BITAC site was measured in the AQMP laboratory. The aerosol masses of both the $\mathrm{PM}_{10}$ and $\mathrm{PM}_{2.5}$ fractions were determined by weighing the filters before and after exposure using a microbalance (METTLER Model MT5). A Po-210 (alpha emitter) electrostatic charge eliminator (STATICMASTER) was used to eliminate the static charge accumulated on the filters before each weighing ${ }^{(22)}$.

The concentration of $\mathrm{BC}$ in both $\mathrm{PM}_{10}$ and $\mathrm{PM}_{2.5}$ samples were determined by reflectance measurement in AECD laboratory using an (EEL) type Smoke Stain Reflectometer ${ }^{(23)}$. Secondary standards of known black carbon concentrations were used to calibrate the reflectometer. The concentrations are defined based on the amount of reflected light that is absorbed by the filter sample and an assumed mass absorption coefficient. It is related to the concentration of light absorbing carbon through standards of carbon with known areal density. Iron $(\mathrm{Fe})$ has a moderate light absorption coefficient 
and can have some limited influence on the $\mathrm{BC}$ value measured by reflectance. The uncertainty associated with the BC measurement is moderate (4-9\%), and therefore, the influence of variation in Fe concentration on $\mathrm{BC}$ measurement has been neglected.

The OC was estimated from suitable EC (BC)/TC ratios obtained from literature. Emissions from diesel engines as well as from oil- and coal-fired stationary sources exhibit EC $(\mathrm{BC}) / \mathrm{TC}$ ratios $^{(24,25)}$ in the range of 0.6-0.7.

\subsection{Meteorological Data}

In Bangladesh, the climate is characterized by high temperature and high humidity during most of the year and also distinctly marked seasonal variation of precipitation. According to meteorological condition ${ }^{(16)}$, the year can be divided into four seasons, pre-monsoon (March-May), monsoon (June-September), post-monsoon (October-November) and winter (December-February). The meteorological data used in this study was obtained from local meteorological station, which is located about 5 kilometers northwest of BITAC site. The prevailing seasonal wind direction patterns based on the meteorological data are given in Figure 2. It is seen that wind direction changes with seasons and four distinct directional patterns observed in each season.

\subsection{Elemental Analysis}

A radioisotope-induced energy dispersive X-ray fluorescence $(\mathrm{EDXRF})^{(26,27)}$ Spectrometer was used to analyze the elemental composition of all of the filter samples. Energy-Dispersive X-Ray Fluorescence (EDXRF) analysis employs detectors that directly measure the energy as well as the intensity of the X-rays by collecting ionization produced in a suitable detecting medium. The EDXRF analysis based on Cd-109 radioisotope (emitting Ag-K x-rays) excitation has been used for the present study. The main components of the EDXRF system consists of a primary x-ray source (Cd-109), sample holder, an x-ray detector, multichannel analyzer (MCA) and associated NIM
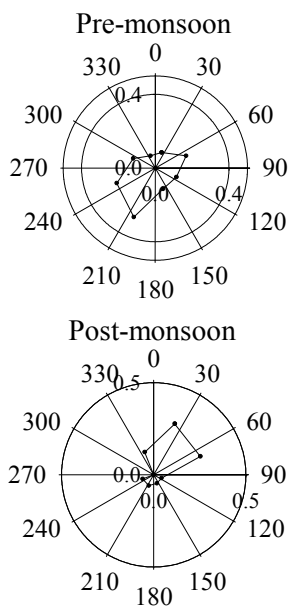
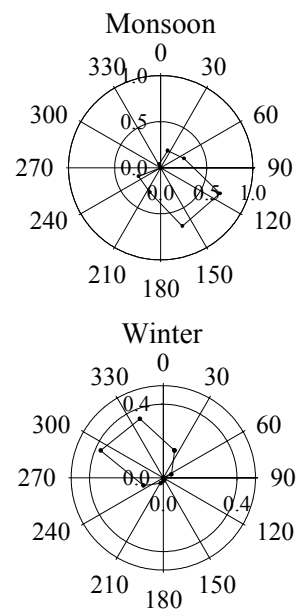

Fig. 2. Seasonal wind direction at Dhaka based on wind speed data. 
(Nuclear Instrument Module) electronics for data acquisition and processing. The EDXRF spectra were processed and quantified using the Qualitative X-ray Analysis System (QXAS) and the Analysis of X-ray spectra by an Iterative Least-square fitting $(\text { AXIL })^{(27)}$. All samples were analyzed using a live time of 3000s. Calibration of the EDXRF spectrometer was performed using MicroMatter thin standards (MicroMatter Co., Eastsounds, WA, USA) of suitable concentrations. Because of the limitations of the $\mathrm{XRF}$ system, only 4 elements: $\mathrm{Fe}, \mathrm{Cu}, \mathrm{Zn}$, and $\mathrm{Pb}$ could be determined. The values of $\mathrm{Al}, \mathrm{Si}, \mathrm{Ti}$ and $\mathrm{Ca}$ have calculated from $\mathrm{Mason}^{(28)}$ data.

\section{RESULT AND DISCUSSION}

\section{Reconstructed mass (RCM)}

The analysis of PM samples provided elemental BC and OC concentrations. These values permit the development of fingerprints for a variety of particle sources. It is also useful to combine selected elements to estimate the concentrations of composite compositions to represent the most likely form of the measured element such as estimating the amount of ammonium sulfate from the measured sulfur concentration. It is also possible to derive other combinations of elements that represent interesting aerosol components. These combinations are called pseudo-elements such as "soil" (29). Thus, these composite variables and pseudo-elements help provide a better understanding of possible sources and their contributions to the average ambient aerosol.

Soil : Windblown soil is composed mainly of the oxides of $\mathrm{Mg}, \mathrm{Al}, \mathrm{Si}, \mathrm{Ca}, \mathrm{Ti}$ and Fe with other many trace elements. The average composition of sandstone and sedimentary rocks and the summation of the 5 major oxides of $\mathrm{Al}, \mathrm{Si}, \mathrm{Ca}, \mathrm{Ti}$ and $\mathrm{Fe}$ account for more that $85 \%$ of the total composition. So the equation for soil is

$$
\text { Soil }=2.20 * A l+2.49 * S i+1.63 * C a+1.94 * T i+2.42 * F e
$$

This equation assumes that the two common oxides of iron $\mathrm{Fe}_{2} \mathrm{O}_{3}$ and $\mathrm{FeO}$ occur in equal proportions. The factor of 2.42 for iron also includes the estimate for $\mathrm{K}_{2} \mathrm{O}$ in soil through the $(K / F e)=0.6$ ratio for sedimentary soils. The sum of all of the composite variables is expected to provide a reasonable estimate of $\mathrm{PM}_{10}$ and $\mathrm{PM}_{2.5}$ mass for comparison with the measured gravimetric mass collected on the filters. The definition of the reconstructed mass is,

$$
R C M=\left(\mathrm{NH}_{4}\right)_{2} \mathrm{SO}_{4}+\mathrm{Salt}+\mathrm{Soil}+\mathrm{Zn}+\mathrm{Pb}+\mathrm{BC}+\mathrm{OC}
$$

Where $\left(\mathrm{NH}_{4}\right)_{2} \mathrm{SO}_{4}$, and Salt are the terms for sulphate and sea salt. Because of the analytical limitations, these terms have been omitted for lack of the data needed to estimate their concentrations.

\section{PM and BC concentrations}

Twelve $\mathrm{PM}_{10}$ and $\mathrm{PM}_{2.5}$ samples were collected and analyzed for gravimetric mass, black carbon and elemental concentrations during the study. Table 1 shows the daily $\mathrm{PM}_{2.5} / \mathrm{PM}_{10}, \mathrm{BC} / \mathrm{PM}_{2.5}, \mathrm{BC} / \mathrm{PM}_{10}$ mass ratios during the sampling period. The data indicates that in majority of the days more than $50 \%$ of the $\mathrm{PM}_{10}$ mass are fine particles with aerodynamic diameter less than $2.5 \mu \mathrm{m}$, which are mainly are of anthropogenic 
origin. It may be due to the influence of traffic-induced dust from abrasion and resuspension, which is dominated by exhaust pipe emissions and other anthropogenic activities like industrial emissions as. It has been found that about $25 \%$ of $\mathrm{PM}_{2.5}$ is $\mathrm{BC}$ mass. On the other hand about $16 \%$ of $\mathrm{PM}_{10}$ is $\mathrm{BC}$ mass. Transport related emissions are major source of $\mathrm{BC}$ and long-range transportation from fossil fuel related sources and biomass burning could be other substantial sources of $\mathrm{BC}^{(30)}$. $\mathrm{BC}$ has a higher contribution during the dry season. Black carbon $(\mathrm{BC})$ is a tracer of primary anthropogenic emissions and its variability reflects changes in source strengths, longrange transport and atmospheric mixing characteristics.

Table. 1.

The ratios of $\mathrm{BC} / \mathrm{PM}_{10}, \mathrm{BC} / \mathrm{PM}_{2.5}$ and $\mathrm{PM}_{2.5} / \mathrm{PM}_{10}$ during the sampling period.

\begin{tabular}{|l|c|c|c|c|c|c|c|}
\hline Date & $\mathbf{P M}_{\mathbf{1 0}}$ & $\mathbf{P M}_{\mathbf{1 0} \_} \mathbf{B C}$ & $\mathbf{P M}_{\mathbf{2 . 5}}$ & $\mathbf{P M}_{\mathbf{2 . 5}} \mathbf{B C}$ & $\mathbf{B C} / \mathbf{P M}_{\mathbf{1 0}}$ & $\mathbf{B C}_{\mathbf{P} \mathbf{P}_{\mathbf{2 . 5}}}$ & $\mathbf{P}_{\mathbf{2 . 5}} \mathbf{P}$ \\
\hline $11 / 05 / 06$ & 229 & 38.9 & 161 & 38.6 & 0.17 & 0.24 & 0.70 \\
\hline $12 / 10 / 06$ & 354 & 60.2 & 240 & 43.2 & 0.17 & 0.18 & 0.68 \\
\hline $01 / 14 / 07$ & 392 & 62.7 & 242 & 43.6 & 0.16 & 0.18 & 0.62 \\
\hline $01 / 21 / 07$ & & & 364 & 69.2 & & 0.19 & \\
\hline $01 / 27 / 07$ & 466 & 74.6 & & & 0.16 & & \\
\hline $02 / 03 / 07$ & 208 & 27.0 & & & 0.13 & & \\
\hline $02 / 04 / 07$ & & & 118 & 21.2 & & 0.18 & \\
\hline $02 / 25 / 07$ & 158 & 22.1 & 94 & 31.9 & 0.14 & 0.34 & 0.59 \\
\hline $03 / 11 / 07$ & 274 & 43.8 & 150 & 34.5 & 0.16 & 0.23 & 0.55 \\
\hline $04 / 15 / 07$ & 166 & 24.9 & 127 & 44.5 & 0.15 & 0.35 & 0.77 \\
\hline $04 / 22 / 07$ & 137 & 28.8 & & & 0.21 & & \\
\hline $04 / 29 / 07$ & 284 & 48.3 & 119 & 44.0 & 0.17 & 0.37 & 0.42 \\
\hline
\end{tabular}

The average $\mathrm{PM}_{10}, \mathrm{PM}_{2.5}$ and $\mathrm{BC}$ concentrations are compared with those concentrations measured in a separate study during the sampling period at a semi-residential area at Dhaka and is given in Table 2. In general, both PM and BC concentrations in the study area are significantly higher than the corresponding concentrations at semi-residential area. It is also observed that the ratio of $\mathrm{PM}_{2.5} / \mathrm{PM}_{10}$ in study area is about 1.65 times higher than the ratio of $\mathrm{PM}_{2.5} / \mathrm{PM}_{10}$ at semi residential area (Table 2). This higher ratio indicates that relative $\mathrm{PM}_{2.5}$ fraction i.e., anthropogenic component of $\mathrm{PM}$ is higher at the study area. The main reason of higher $\mathrm{PM}_{2.5}$ fraction expected to be the influence of many small industries like metal workshop, galvanizing factory etc. surrounding the sampling site. Moreover, traffic related emission from the busy road with higher traffic density along the western side of the sampling site which links the northern and southern part of Dhaka city might have additional influence on the observed higher $\mathrm{PM}_{2.5}$ concentration 
Table. 2.

Comparison of $\mathrm{PM}_{10}, \mathrm{PM}_{2.5}$ and $\mathrm{BC}$ concentrations $\left(\mu \mathrm{g} / \mathrm{m}^{3}\right)$ at semi-residential area and BITAC site

\begin{tabular}{|c|c|c|c|c|}
\hline \multirow{2}{*}{ Parameter } & \multicolumn{2}{|c|}{ Semi-residential area } & \multicolumn{2}{c|}{ Study area } \\
\cline { 2 - 5 } & Average & SD & Average & SD \\
\hline $\mathrm{PM}_{10}$ & 115 & 28.6 & 267 & 109 \\
\hline $\mathrm{PM}_{2.5}$ & 39.9 & 8.29 & 153 & 97.1 \\
\hline $\mathrm{BC}$ & 10.3 & 5.50 & 43.1 & 22.4 \\
\hline
\end{tabular}

Time series of PM concentration and dependence on meteorology

The time series of the average 24-h $\mathrm{PM}_{2.5}$ and $\mathrm{PM}_{10}$ mass concentrations were analyzed throughout the sampling period (Figure 3). The 24-h average values for both $\mathrm{PM}_{10}$ and $\mathrm{PM}_{2.5}$ masses are much higher than the Bangladesh national air quality standard, which are set at $165 \mu \mathrm{g} / \mathrm{m}^{3}$ and $65 \mu \mathrm{g} / \mathrm{m}^{3}$, respectively. The major source of $\mathrm{PM}_{2.5}$ comes from anthropogenic activities ${ }^{(31)}$. It has found that during wintertime the concentration of both $\mathrm{PM}_{10}$ and $\mathrm{PM}_{2.5}$ have increasing trend and the concentration decreases with the change of the season (Figure 3).

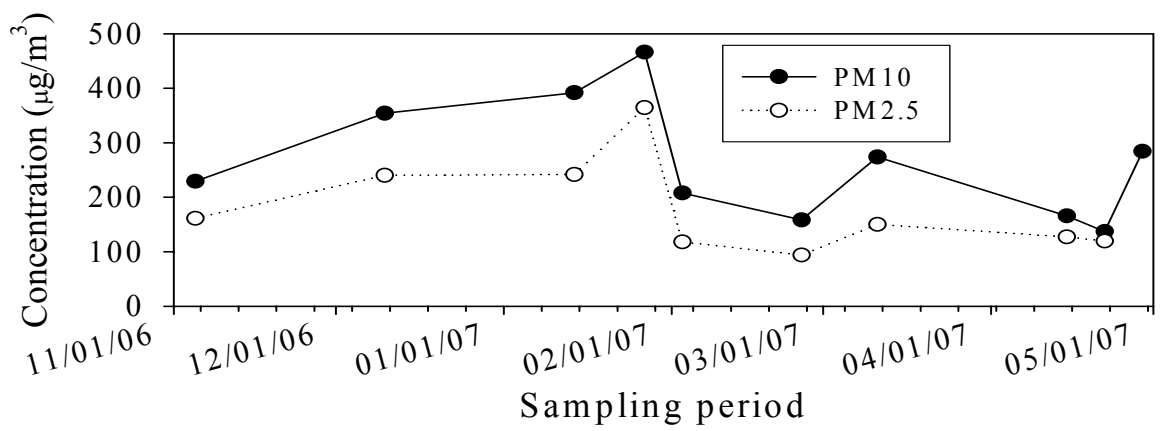

Fig. 3. The time series of $\mathrm{PM}_{2.5}$ and $\mathrm{PM}_{10}$ during the sampling period

The reasons for the higher PM concentration during the winter are not only seasonal fluctuations of the emissions from local sources, but also meteorological effects. According to the meteorological conditions (Figure 2), it is well known that during the wintertime wind mainly comes from the north and northwest directions ${ }^{(32)}$. Figure 4 shows the plot of $\mathrm{PM}_{2.5}$ mass concentration, Rainfall and Wind Speed to observe the dependence of $\mathrm{PM}_{2.5}$ concentration on those meteorological parameters. It is found that with the increase of wind speed during this dry season, the $\mathrm{PM}_{2.5}$ mass increases (Figure 4) and relative humidity did not show any significant influence on $\mathrm{PM}_{2.5}$ concentration. 


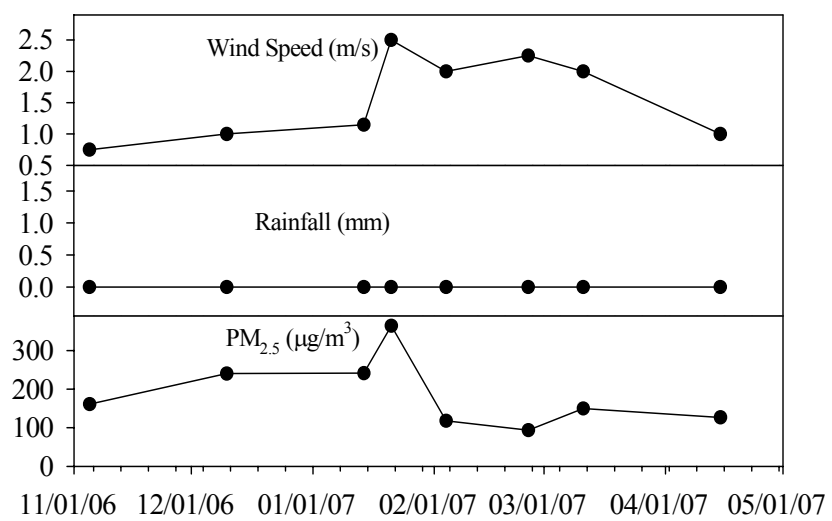

Fig. 4. Variation of $\mathrm{PM}_{2.5}$ mass with the change of meteorological parameters during the sampling time

Since $\mathrm{PM}_{2.5}$ fractions have relatively high residence time, this fraction could have regional contribution apart from local source contribution. It was observed from the wind direction that during the wintertime, the wind comes mainly from north and northwest directions $^{(32)}$. The Hybrid Single Particle Lagrangian Integrated Trajectory (HYSPLIT 4) model ${ }^{(33)}$ was used to calculated the air mass backward trajectories for days with high impacts of fine particles are shown in Figure 5. Backward trajectories starting at height of $500 \mathrm{~m}$ above the ground level were computed using the vertical mixing model. Figure 5 shows the contribution on 21 January 2007 was likely due to contribution from north and northwesterly direction. The results indicate that PM concentrations in winter are also influenced by transboundary air pollution.

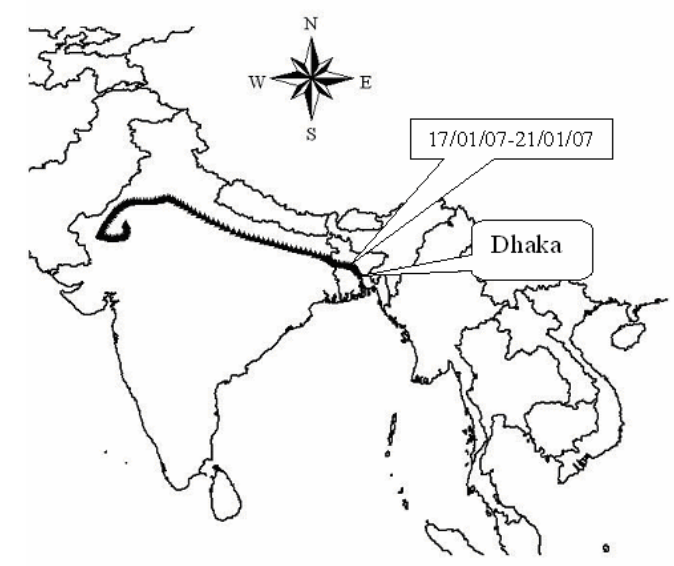

Fig. 5. Backward trajectories arriving Dhaka on 21 January 2007 computed at the NOAA Air Resources Laboratory HYSPLIT site 


\section{Factor Analysis}

The trends in data monitored were analyzed using an approach based on factor analysis to identify qualitatively the sources contributing to the pollution. The number of parameters that have been used in factor analysis is given in Table 3.

Table. 3.

Mean and standard deviations of PM mass, BC and elemental concentration at BITAC site (concentrations in $\mu \mathrm{g} / \mathrm{m}^{3}$ ) during the sampling period

\begin{tabular}{|c|c|c|c|c|}
\hline \multirow{2}{*}{ Parameter } & \multicolumn{2}{|c|}{ PM$_{\mathbf{2 . 5}}$} & \multicolumn{2}{c|}{ PM $_{\mathbf{1 0}}$} \\
\cline { 2 - 5 } & Average & SD & Average & SD \\
\hline Mass & 153.4 & 97.1 & 266.8 & 109.1 \\
\hline $\mathrm{BC}$ & 43.1 & 22.4 & 32.9 & 11.5 \\
\hline $\mathrm{OC}$ & 28.9 & 15.01 & 22.1 & 7.72 \\
\hline $\mathrm{Al}$ & 4.6 & 1.29 & 11.0 & 3.56 \\
\hline $\mathrm{Si}$ & 15.7 & 4.4 & 37.8 & 12.2 \\
\hline $\mathrm{Ca}$ & 2.31 & 0.65 & 5.56 & 1.80 \\
\hline $\mathrm{Ti}$ & 0.31 & 0.09 & 0.76 & 0.24 \\
\hline $\mathrm{Fe}$ & 3.14 & 0.88 & 7.54 & 2.44 \\
\hline $\mathrm{Cu}$ & 0.63 & 0.17 & 0.43 & 0.24 \\
\hline $\mathrm{Zn}$ & 1.80 & 1.35 & 2.29 & 2.53 \\
\hline $\mathrm{Pb}$ & 4.73 & & 1.70 & 1.46 \\
\hline
\end{tabular}

To address the air quality issues, it is always necessary to have information on possible source contribution to the pollutants. In order to produce the best possible source resolutions, it is important to have accurate measurements of the particulate mass as well as determinations for as many as elements as possible. As a prerequisite for factor analytic method a value is required for each data point of the sample matrix including those values that are below the detection limits. In XRF system, the detection limit is much higher than PIXE technique. Therefore a good approach to providing these values are to use a uniform random number generator to provide a number between zero and the detection limit. Thus, multiplying this function by the detection limit will provide a useful value. In order to obtain a reliable estimate of different sources from PM mass concentrations measured at BITAC area of Tajgaon industrial area, Dhaka, Principal Components Analysis (PCA) was used to identify major elements associated with sources. Table 4 and 5 show the factor loadings for $\mathrm{PM}_{2.5}$ and $\mathrm{PM}_{10}$ samples respectively obtained from PCA analysis using STATGRAPHICS software. Factors with two or more elements having factor loadings above 0.3 have been highlighted. Four factors could explain $100 \%$ of the sample variance for both fraction of particulate matter collected from BITAC. Factor loading near 1.0 demonstrate that the element has a strong association with that individual factor.

Table. 4.

Principal Components Analysis (PCA) with varimax rotation for all $\mathrm{PM}_{2.5}$ data from BITAC

\begin{tabular}{|l|c|c|c|c|c|}
\hline $\begin{array}{l}\text { Para } \\
\text { meter }\end{array}$ & Soil & $\begin{array}{l}\text { Motor vehicle \& } \\
\text { Biomass Burning }\end{array}$ & $\begin{array}{l}\text { Zn } \\
\text { source }\end{array}$ & $\begin{array}{l}\text { Metal } \\
\text { Workshop }\end{array}$ & Communality \\
\hline $\mathrm{BC}$ & 0.072 & $\mathbf{0 . 9 9 0}$ & 0.104 & 0.054 & 1.00 \\
\hline $\mathrm{OC}$ & 0.071 & $\mathbf{0 . 9 9 0}$ & 0.106 & 0.054 & 1.00 \\
\hline $\mathrm{Fe}$ & $\mathbf{0 . 9 8 6}$ & 0.063 & 0.097 & 0.118 & 1.00 \\
\hline $\mathrm{Cu}$ & $\mathbf{0 . 6 9 6}$ & 0.202 & 0.165 & $\mathbf{0 . 6 6 9}$ & 1.00 \\
\hline $\mathrm{Zn}$ & 0.159 & 0.173 & $\mathbf{0 . 9 7 0}$ & 0.066 & 1.00 \\
\hline $\mathrm{Si}$ & $\mathbf{0 . 9 8 6}$ & 0.063 & 0.096 & 0.119 & 1.00 \\
\hline $\mathrm{Al}$ & $\mathbf{0 . 9 8 6}$ & 0.064 & 0.096 & 0.119 & 1.00 \\
\hline $\mathrm{Ca}$ & $\mathbf{0 . 9 8 6}$ & 0.065 & 0.097 & 0.117 & 1.00 \\
\hline $\mathrm{Ti}$ & $\mathbf{0 . 9 8 6}$ & 0.069 & 0.092 & 0.116 & 1.00 \\
\hline \% Var. & 65.4 & 22.4 & 9.04 & 3.16 & Total $100 \%$ \\
\hline Eigen & 5.88 & 2.02 & 0.81 & 0.28 & \\
\hline
\end{tabular}




\section{Source fingerprints}

Utilizing factor analytic technique, four sources could be identified for the $\mathrm{PM}_{2.5}$ samples collected from the community. The identified sources are attributed to soil dust, motor vehicle, motor vehicle and biomass burning and $\mathrm{Zn}$ source. Factor 1 in Table 5 explained $65 \%$ of the variance and included the elements $\mathrm{Al}, \mathrm{Si}, \mathrm{Ti}, \mathrm{Ca}$, and $\mathrm{Fe}$, which were recognized as typical soil indicators. Factor 2 explained $22 \%$ of the variance and was labeled Motor vehicle together with biomass burning/brick kiln as it included high factor loading for BC and OC. Factor 3 explained 9\% of the variance and was labeled as $\mathrm{Zn}$ source. It suggests part of this source contribution might be from motor vehicles, especially those from old vehicles, transports with two-stroke engines such as motor cycle/motor scooter. In two-stroke engine, fuel and lubricant are mixed and burnt together in the piston chambers and old vehicles with worn-out pistons also consume lubricants with fuel. $\mathrm{Zn}$ is added in the lubricant. Thus, during combustion, $\mathrm{Zn}$ in the lubricant is emitted from such vehicles. Zn could also come from galvanized materials, tire wires and the use of zinc compounds in rubber production ${ }^{(34)}$. Factor 4 explained $3 \%$ of the variance and was labeled as Metal workshop as $\mathrm{Cu}$ comes from foundries.

In $\mathrm{PM}_{10}$ samples, the identified sources are attributed to soil dust, motor vehicle, and fugitive $\mathrm{Pb}$ and $\mathrm{Zn}$ source. Factor 1 in Table 5 explained $70 \%$ of the variance and included the elements $\mathrm{Al}, \mathrm{Si}, \mathrm{Ca}$, and $\mathrm{Fe}$, which were recognized as typical soil indicators. This factor is also mixed with $\mathrm{BC}$ and $\mathrm{OC}$ which is the indicator of motor vehicle. Factor 2 explained $12 \%$ of the variance and was labeled as Metal workshop source. Factor 3 explained $11 \%$ of the variance and was labeled fugitive $\mathrm{Pb}$ source. Although, $\mathrm{Pb}$ has been eliminated from the gasoline in Bangladesh since July $1999^{(23)}$, there may be substantial accumulated lead in the dust near roadways. There is also some $\mathrm{Pb}$ from leadacid battery recycling plants. Factor 4 explained $7 \%$ of the variance and was labeled as $\mathrm{Zn}$ source. It suggests that part of this source contribution might be from motor vehicle, especially those of two-stroke engines such as motor cycle/motor scooter. In two-stroke engine, fuel and lubricant are mixed and burnt together in the piston chambers. $\mathrm{Zn}$ is added in the lubricant. Thus, during combustion, $\mathrm{Zn}$ is emitted from the two-stroke engines. Zn could also be contributed from galvanized materials, tire wire and the use of zinc compounds in rubber production ${ }^{(34)}$.

Table. 5.

Principal Components Analysis (PCA) with varimax rotation for all $\mathrm{PM}_{10}$ data from BITAC

\begin{tabular}{|l|c|c|c|c|c|}
\hline Parameter & $\begin{array}{l}\text { Soil \& Motor } \\
\text { vehicle }\end{array}$ & $\begin{array}{c}\text { Metal } \\
\text { Workshop }\end{array}$ & $\begin{array}{c}\text { Fugitive } \\
\text { Pb }\end{array}$ & Zn source & $\begin{array}{c}\text { Communalit } \\
\text { y }\end{array}$ \\
\hline $\mathrm{BC}$ & $\mathbf{0 . 9 6 3}$ & -0.052 & 0.217 & 0.122 & 0.99 \\
\hline $\mathrm{OC}$ & $\mathbf{0 . 9 6 3}$ & -0.055 & 0.216 & 0.125 & 0.99 \\
\hline $\mathrm{Fe}$ & $\mathbf{0 . 9 6 0}$ & 0.235 & 0.132 & 0.054 & 1.00 \\
\hline $\mathrm{Cu}$ & 0.195 & $\mathbf{0 . 9 5 8}$ & 0.190 & 0.057 & 1.00 \\
\hline $\mathrm{Zn}$ & 0.120 & 0.052 & -0.030 & $\mathbf{0 . 9 9 1}$ & 1.00 \\
\hline $\mathrm{Pb}$ & 0.279 & 0.207 & $\mathbf{0 . 9 3 7}$ & -0.038 & 1.00 \\
\hline $\mathrm{Si}$ & $\mathbf{0 . 9 6 0}$ & 0.237 & 0.135 & 0.052 & 1.00 \\
\hline $\mathrm{Al}$ & $\mathbf{0 . 9 6 0}$ & 0.237 & 0.135 & 0.052 & 1.00 \\
\hline $\mathrm{Ca}$ & $\mathbf{0 . 9 6 0}$ & 0.236 & 0.135 & 0.052 & 1.00 \\
\hline \% Var. & 69.9 & 12.2 & 10.8 & 6.76 & \multirow{2}{*}{ Total $100 \%$} \\
\hline Eigen & 6.30 & 1.10 & 0.97 & 0.61 & \\
\hline
\end{tabular}




\section{Source apportionment from Reconstructed Mass (RCM)}

The available elemental, $\mathrm{OC}$ and $\mathrm{BC}$ concentration data were used to estimate the possible sources and their contributions to the average ambient PM pollutants. The sum of all the composite variables discussed in the previous section would provide a reasonable estimate of the total $\mathrm{PM}_{10}$ and $\mathrm{PM}_{2.5}$ mass for comparison with the measured gravimetric mass of both $\mathrm{PM}_{10}$ and $\mathrm{PM}_{2.5}$ on the Teflon filters. So, the definition of the reconstructed mass $(\mathrm{RCM})$ would be,

$$
R C M=\left(\mathrm{NH}_{4}\right)_{2} \mathrm{SO}_{4}+\mathrm{Salt}+\mathrm{Soil}+\mathrm{OC}+\mathrm{BC}+\mathrm{Zn}+\mathrm{Pb}
$$

The accuracy of this equation was tested by comparing RCM with the gravimetric weight of the PM. The average reconstructed mass (RCM) accounted for about 53-112\% and 53$128 \%$ of the measured mass for $\mathrm{PM}_{10}$ and $\mathrm{PM}_{2.5}$ respectively in this study. As it is not possible to measure some essential elements like $\mathrm{Na}, \mathrm{Mg}, \mathrm{Al}, \mathrm{Si}, \mathrm{P}, \mathrm{Cl}, \mathrm{K}$ with the existing XRF system, therefore the RCM values become lower than $100 \%$ in some cases. On the other hand, OC has been calculated theoretically only considering the diesel vehicle, which gives RCM over $100 \%$. Table 6 gives the percentage of source contributions to $\mathrm{PM}$ from RCM calculation for $\mathrm{PM}_{2.5}$ and $\mathrm{PM}_{10}$ particulate matter collected at BITAC site in Dhaka during the study period.

Table. 6.

Percentage of source contributions to PM from RCM calculation

\begin{tabular}{|l|c|c||}
\hline \multirow{2}{*}{ Parameter } & \multicolumn{2}{|c|}{ BITAC area } \\
\cline { 2 - 3 } & $\mathrm{PM}_{2.5}$ & $\mathrm{PM}_{10}$ \\
\hline Soil dust & 45.8 & 71.5 \\
\hline Black carbon & 31.1 & 16.0 \\
\hline Organic carbon & 20.9 & 10.7 \\
\hline $\mathrm{Zn}$ & 1.39 & 1.11 \\
\hline Fugitive $\mathrm{Pb}$ & 3.55 & 0.83 \\
\hline
\end{tabular}

It is observed that maximum pollution contribution comes from soil dust in $\mathrm{PM}_{10}$ mass ${ }^{(35)}$ and estimated contribution is over $72 \%$. In case of $\mathrm{PM}_{2.5}$ mass, the highest contributor is combined $\mathrm{BC}$ and $\mathrm{OC}$, which accounts for about $52 \%$ of the total mass and these are mainly related to vehicular emissions. Although maximum fraction of the $\mathrm{BC}$ and $\mathrm{OC}$ expected to be from vehicular emission but $\mathrm{BC} / \mathrm{OC}$ may also originate from the unburned fuel or from the biomass burning/brick kiln ${ }^{(36)}$. About $1 \%$ of the $\mathrm{PM}_{2.5}$ mass is $\mathrm{Zn}$ source, which could be contributed from galvanized materials, tire wear and the use of zinc compounds in rubber production ${ }^{(37)}$.

\section{CONCLUSION}

The site is located close to an intersection of several main roads typically carrying heavy traffics. It was found that the elemental concentrations in PM mass are much higher in the industrial site than the semi-residential area. Both natural and anthropogenic such as industrial and motor vehicle sources are expected to make an important contribution to elevated PM concentrations in this site. The elevated $\mathrm{PM}_{2.5}$ concentration is also to some extent due to transboundary air pollution effect as the samplings were done during the dry season. From FA, it is possible to resolve the sources qualitatively. As the resolved sources are almost similar to the sources identified 
quantitatively by RCM method. Thus, it is possible to identify and apportionment of sources by combining of these two methods.

\section{ACKNOWLEDGEMENT}

The authors wish to thank Director, Atomic Energy Centre, Dhaka (AECD) and Head, Chemistry Division, AECD for their continued support and cooperation throughout the work. The authors are thankful to the staff members of the Chemistry Division for their continuous help during the course of this work.

\section{REFERENCES}

1. D. W. Dockery, F. E. Speizer, D. O. Stram, J. H. Ware, J. D. Spengler, and B. G. Ferris. Effects of inhalable particles on respiratory health of Chieldren. Am. Rev. Diseases 139, 134,1989 .

2. D. J. Dockery, and C. A. Pope. Acute respiratory effects of particulate air pollution. Ann Rev Public Health 15, 107,1994.

3. N. Kato, Y. Ogawa, T. Koike, T. Sakamoto, S. Sakamoto, and R. Group. Analysis of the structure of energy consumption and the dynamics of emissions of atmospheric species related to the global change $\left(\mathrm{SO}_{\mathrm{x}}, \mathrm{NO}_{\mathrm{x}}\right.$ and $\left.\mathrm{CO}_{2}\right)$ in Asia. NISTEP Report no 21, 4th Policy-oriented Research Group, National Institute of Science and Technology Policy, Tokyo.,1991.

4. Bangladesh. Country Environmental Analysis, Bangladesh Development Series Paper No: 12, www.worldbank.org.bd/bds.2006.

5. J. Heinrich, M. Pitz, W. Bischof, N. Krug, and P. J. A. Borm. Endotoxin in fine (PM2.5) and coarse (PM2.5-10) particle mass of abmient aerosols. A temporo-spatial analysis. Atmos. Environ. 37, 3659,2003.

6. C. A. Pope, and D. W. Dockery (1999). Epidemiology of particle effects, Academic Press).

7. US-EPA. Air qualilty Criteria for Particulate Matter. 2002.

8. D. D. Cohen, M. Graham, M. Bailey, and R. Kondepudi. Elemental analysis by PIXE and other IBA techniques and their application to source fingerprinting of atmospheric fine particle pollution. Nuclear Instrumental Method (B) 109, 218,1996.

9. D. D. Cohen. Characterization of atmospheric fine particle using IBA techniques,. Nuclear Instrumental Methods (B) 136, 14,1998.

10. D. W. Dockery, C. A. Pope, X.Xu, J. D. Spengler, J. H. Ware, M. E. Fay, B. G. Ferris, and F. E. Speizer. An Association between Air Pollution and Mortality in six US Cities. New England Journal of Medicine 329, 1753,1993.

11. IPCC. The third assessment report of working group I of the intergovernmental panel on climate change, technical summary, lead authors, D.L. Albritton (USA), L.G. Meira Filho (Brazil), Shanghai. 2001.

12. K. H. Kim, J. H. Lee, and M. S. Jang. Metals in airborne particulate matter from the first and second industrial comples area of Taejon city, Korea. Environmental Pollution 118, 41,2002.

13. A. Samura, O. Al-Agha, and S. G. Tuncel. Study of trace and heavy metals in rural and urban aerosols of Uludag and Bursa (Turkey). Water, Air and Soil Pollution: Focus 3, 109,2003.

14. L. Hernandez, A. Probst, J. L. Probst, and E. Ulrich. Heavy metal distribution in some French forest soils:evidence for atmospheric contaminant. Science of the Total Environment 312, 195,2003 . 
15. S. E. Kakula. Trace metal concentration in roadside surface soil and tree back: Ameasurement of local atmospheric pollution in Abuja, Nigera. Envronmental Monitoring Assessment 89, 233,2003

16. A. Salam, H. Bauer, K. Kassin, S. M. Ullah, and H. Puxbaum. Aerosol chemical characteristics of a mega-city in Southeast Asia (Dhaka, Bangladesh). Atmospheric Environment 37, 2517,2003.

17. P. Kassomenos, V. Kotroni, and G. Kallos. Analysis of climatological and air quality observations from greater Athens area. Atmos. Environ. 29B, 3671,1995.

18. A. Chaloulakou, D. Assimacopoulos, and T. Lekkas. Forecasting daily maximum O3 concentrations in the Athens Basin. Environmental Monitary and Assessment 56, 2559,1999.

19. B. A. Begum, S. K. Biswas, E. Kim, P. K. Hopke, and M. Khaliquzzaman. Investigation of sources of atmospheric aerosol at a hot spot area in Dhaka, Bangladesh. J. Air and Waste Management Association 55, 227,2005.

20. A. MiniVol Portable Air Sampler, 225 5th street suit 501, Springfield, Oregon 97477, U.S.A.

21. B. A. Begum, and S. K. Biswas. Comparison of PM collection efficiency of Gent and Airmatrics MiniVol Portable Air Sampler. Nuclear Science and Application I14, 79,2005.

22. B. A. Begum, S. Akhter, L. Sarker, and S. K. Biswas. Gravimetric analysis of Air Filters and Quality Assurance in Weighing. Nuclear Science and Application In press,2007.

23. S. K. Biswas, S. A. Tarafdar, A. Islam, M. Khaliquzzaman, H. Tervahattu, and K. Kupiainen. Impact of unleaded gasoline introduction on the concentration of lead in the air of Dhaka, Bangladesh. J. Air and Waste Management Association 53, 1355,2003.

24. G. R. Cass, P. M. Boone, and E. S. Macias. Emission and air quality relationships for atmospheric carbon particles in Loss Angeles, Particulate carbon: Atmospheric Life Cycle, ed. G.T.Wolff and R.L. KlimischPlenum Press, New York.1982.

25. J. A. Rau. Aerosol Science and Technology 10, 181,1989.

26. P. Molnar, P. Gustafson, S. Johannesson, J. Boman, L. Barregard, and G. Sallsten. Domestic wood burning and PM2.5 trace elements: Personal exposure, indoor and outdoor levels. Atmos. Environ. 39, 2643,2005.

27. G. Bernasconi, A. Tajani, and P. Kregsamer. Mannual for QXAS/AXIL. Version 3.5, IAEA, Vienna.2000.

28. R. Mason. Priciples of Geochemistry, Wiley, New York.1966.

29. W. C. Malm, J. F. Sisler, D. Huffman, R. A. Eldred, and T. A. Cahill. Spatial and seasonal trends in particle concentration and optical extinction in the United States. J. Geophysical Research 99, 1347,1994.

30. J. Viidanoja, M. Sillanpaa, J. Laakia, V.-M. Kerminen, R. Hillamo, P. Aarnio, and T. Koskentalo. Organic and black carbon in PM2.5 and PM10: 1 year of data from an urban site. 2002 .

31. B. A. Begum, E. Kim, S. K. Biswas, and P. K. Hopke. Investigation of sources of atmospheric aerosol at urban and semi-urban areas in Bangladesh. Atmos. Environ. 38, 3025,2004.

32. B. A. Begum, S. K. Biswas, and P. K. Hopke. Temporal variations and spatial distribution of ambient PM2.2 and PM10 concentrations in Dhaka, Bangladesh. The Science of the Total Environment 358, 36,2006.

33. R. R. Draxler, and G. D. Rolph. HYSPLIT 4(Hybrid Single-Particle Lagrangian Integrated Trajectory) Model access via NOAA ARL READY Website (http://www.arl.noaa.gov/ready/hysplit4.html). NOAA Air Resources Laboratory, Silver Spring, MD.2003. 
34. B. A. Begum, S. K. Biswas, E. Kim, P. K. Hopke, and M. Khaliquzzaman. Investigation of sources of atmospheric aerosol at a hot spot area in Dhaka, Bangladesh. J. Air and Waste Management Association, In press,2004.

35. B. A. Begum, and B. Swapan K. Characteristics of particulate matter at two Traffic hot spot areas in Dhaka city. Nuclear Science and Application Submitted,2007.

36. B. A. Begum, P. K. Hopke, and W. Zhao. Source identification of fine particles in Washington, DC, by expanded factor analysis modeling. Environmental Science and Technology 39, 1129,2005.

37. J. E. Fergussion, and N. D. Kim. Trace elements in street and house dust: source and speciation. Science of the total Environment 100,125,1991.

Journal of Bangladesh Academy of Sciences, Vol. 33, No. 1, 71-85, 2009 